\title{
Die Post-Postmoderne
}

\section{Rouven Porz}

PD Dr. phil., dipl. biol., Leiter der Fachstelle für klinische Ethik der Insel Gruppe AG (Bern), Gastwissenschaftler der VU Amsterdam, Präsident der European Association of Centres of Medical Ethics (EACME) und Mitglied der Redaktion Ethik der SÄZ

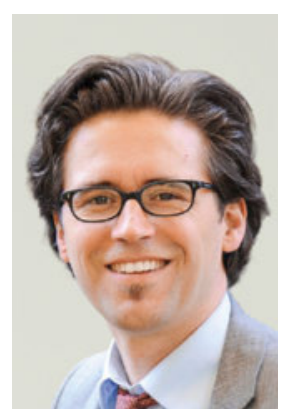

Haben Sie sich schon mal gefragt, in welcher Zeitepoche Sie gerade leben? Die Frage ist an sich unbeantwortbar, weil sich die Menschen bzw. Cyborgs wahrscheinlich erst in fünfzig bis hundert Jahren darauf einigen werden, wie sie unsere Zeit rückblickend benennen wollen. Trotzdem finde ich die Frage spannend, denn sie enthält für mich auch grundlegende ethische Implikationen in Bezug auf unser Handeln heute im Gesundheitswesen. Dazu unten mehr.

Klar ist schon mal, dass wir die Zeitspanne von vor ungefähr hundert Jahren beginnend - sagen wir mal ganz rund von 1900 an bis vielleicht 1960 - als «Moderne» bezeichnen. Die aufgeklärte, Individuen-bezogene Säkularisierung des gesellschaftlichen Lebens, Rationalität und ein starker Fortschrittsglaube, dies basierend auf den neuen Lebenschancen dank industrieller Revolution und Massenproduktion, das sind - aus heutiger Sicht - sicherlich die Kernzutaten der Moderne. Das hatte Auswirkungen auf klare Formen in der Architektur, subjektivierte Literatur und natürlich ein Verständnis von Ethik, das auf klare moralische Prinzipien abzielt. Ausgehend von Immanuel Kants paradigmatischen Aufklärungsschriften und seinem kategorischen Imperativ liegt fortan auch der ethische Schwerpunkt auf dem Individuum, seiner bzw. ihrer Autonomie, und man muss nicht lange nachdenken, um zu realisieren, dass der medizinethische Fokus auf Selbstbestimmung genau hier seinen Nährboden fand, und die Wertschätzung der Patienten-Arzt-Situation, d.h. die Abnahme des ärztlichen Paternalismus korrelierend mit der Zunahme der gelebten Selbstbestimmung des Patienten (wenn vielleicht auch erst ab den 1980ern) ausgelebt wurde.

Dann kam die "Postmoderne», die 68er-Generation. Ironisch wurden alle Errungenschaften der Moderne sukzessive "dekonstruiert» und weggetanzt, der Vernunft wurde die Vernunft abgesprochen, lieber Affekt und Emotion, Wahrheitsansprüche wurden kritisch weggelacht. Die grosse Zeit der Religion, Mythen und Moral war vorbei. Toleranz, Freiheit, Sex, Drugs and Rock 'n' Roll. Radikale Pluralität in der Gesellschaft und in der Ethik die Betonung auf Kontext, Beziehungen, das Konzept der relationalen Autonomie war geboren. Es zählt nicht mehr nur das Arzt-Patienten-Ge- schehen, das gesamte Netzwerk wird wichtig, unzählige Gesundheitsfachberufe rücken ins Geschehen, Verwandte, Angehörige, Haustiere - puh -, es wird unübersichtlich.

Ich gebe zu, viele Ärztinnen und Ärzte wissen vielleicht gar nicht, dass sie schon lange in der Postmoderne operieren (ich glaube, man muss das auch nicht wissen), aber mich dünkt: Die Postmoderne ist vorbei. Sie hat ausgespielt. Gerade in dem Moment zum Beispiel, in dem das ironische Weglachen von Vernunft zur Wahl eines US-Präsidenten wie Donald Trump geführt hat, just in dem Moment haben viele von uns erschreckt und mit einem Kloss im Hals - die knallbunten Türen der Postmoderne innerlich geschlossen und sich still gefragt: Und jetzt? Zurück zur Moderne oder wie? Was folgt denn jetzt auf die ganze dekonstruierte Ironie und den bitteren Relativismus der Postmoderne?

Wir müssen aber nicht bis zum US-Präsidenten gehen (dem ich auch gar nicht zu nahe treten will). Wir können in unserem Gesundheitswesen bleiben: Schuldzuweisungen gegenüber den überbordenden ökonomischen Anreizen, Überforderung durch die Selbstbestimmung der Patienten, wunscherfüllende Medizin, Big Data, neue personalisierte Medizinmythen, Schichtwechsel, Verantwortungsabgabe, ein gefährlicher Mix aus modernen und postmodernen Weltanschauungen. Mein Vorschlag: Lassen wir den ganzen Quatsch hinter uns und denken neu. Neues Zeitalter einläuten: Die Post-Postmoderne. Irmtraud Huber [1] spricht hier (aus Sicht der Literaturwissenschaft) vom neuen Zeitalter der "Rekonstruktion" (auf Konstruktion/Moderne und Dekonstruktion/Postmoderne folgend). Das heisst aber auch: Wieder Verantwortung übernehmen, die eigenen moralischen Prinzipien kennen und bekennen, sich verständigen, politisch werden, eingreifen. Das Beste aus der Moderne und der Postmoderne rausziehen, rekonstruieren, neu weiterdenken. Nicht nur jammern, sondern wieder was machen, fürs Gemeinwohl, nicht nur für die eigene Kasse. Sind Sie dabei? Ich bin dabei. Los geht's.

\section{Literatur}

1 Irmtraud Huber: Literature after Postmodernism. Reconstructive Fantasies. Palcrave Macmillan 2014. 